\title{
Comparative Study of two control strategies proportional integral and fuzzy logic for the control of a doubly fed induction generator dedicated to a wind application
}

\author{
Chebel Ahlem ${ }^{1}$, Benretem $\mathbf{A}^{2}$, Dobrev $\mathbf{I}^{3}$, Barkat $\mathbf{I}^{4}$ \\ ${ }^{1,2}$, Laboratory: Electromechanical Engineering, Badji-Mokhtar-Annaba University, Algeria. \\ 3,4 DynFluid Laboratory, Arts et Métiers-Paris Tech, 151, bd The Hospital, France.
}

\begin{tabular}{l} 
Article Info \\
\hline Article history: \\
Received Jan 17, 2019 \\
Revised Jul 8, 2019 \\
Accepted Nov 15, 2019 \\
\hline Keywords: \\
Active and reactive power \\
Doubly fed induction generator \\
Fuzzy logic \\
Proportional Integral (PI) \\
Vector control \\
Wind power
\end{tabular}

Wind power

\begin{abstract}
This paper gives a observe evaluation of a whole wind energy conversion device, the gadget primarily based on a DFIG; to govern independently the active and reactive powers a vector manage with stator flux orientation of the DFIG is used. A comparative have a look at were achieved among the traditional PI controller and fuzzy logic manage to investigate its dynamic and static performances. This research paintings includes the examination of a section earlier, to offer effective assistance, to all those who have to make selections regarding the planning and implementation of wind electricity projects. The primary goal is to model the wind chain and the usage of styles of techniques for the manipulate of this generator to make certain an awesome law we began with the modeling of the wind chain then the modeling of the DFIG and then the usage of the two strategies for the regulation of the latter the complete device is modeled and simulated inside the Matlab/ Simulink. The overall performance and robustness are analyzed and compared by using Matlab/Simulink. The results acquired show the great performances of the fuzzy logic to prove the pleasant of the strength and the stability of wind strength.
\end{abstract}

This is an open access article under the CC BY-SA license.

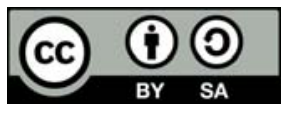

\section{Corresponding Author:}

Chebel Ahlem

Laboratory: Electromechanical Engineering,

Badji-Mokhtar-Annaba University,

23000, Algeria.

Email: chblahlem@gmail.com

\section{INTRODUCTION}

Wind turbine generator is understood and exploited for a long time, it turned into one of the first assets exploited by way of the man after the strength of wood, and it turned into used for the propulsions of the ships and the corn turbines inter alia. It was but neglected at some point of the century with the income of fossil energies besides the hydroelectricity. Inside the Seventies after the oil crisis and the first alarms because of the warming of planet, a new interest is carried to wind power, due to the various technical blessings of wind strength technology era (stepped forward var electricity, decreased power fluctuations and better power performance), variable velocity operation that is carried out by using a conversion system is continually utilized by contemporary MW wind turbines [1].Additionally the development of recent technology returns the conversion of this increasingly worthwhile electricity and economically aggressive, in the worldwide scales, wind power maintains a growth of $30 \%$ in keeping with annum for the remaining decade. Because of the unique blessings of the DFIG, it is turning into the main configuration of wind power technology. The vector control approach is used to study the generator, and the DFIG rotor is connected to an 
alternating excitation whose frequency, section and importance can be tailored [2]. With the DFIG, generation can be accomplished in variable velocity starting from sub-synchronous pace to superb synchronous pace $(( \pm 30 \%)$ around the synchronous pace $)[2,3]$. A manage strategy must be advanced to take advantage of these benefits within the field of wind strength technology thinking of the complexity of the structure of the DFIG and the first-class of the electricity to be generated, due to the shortage or scarcity of control of the asset produced. Regarding the reactive powers whilst the generator is connected to the community, many difficulties get up, which include the low power component and the harmonic pollution. Using an inner functional mode controller predictive of the specific creation and association had been studied, in which a suitable energy reaction is acquired by means of assessment with those of the traditional procedure strength reaction when the traditional PI controller is used. However, it is hard to use one due to the complexity in their structures [4]. On this paper, an alternative method has been proposed the use of a fuzzy common sense controller optimized to check the active and reactive powers across the rotor circuit. Therefore, we favored to use this type of controller (fuzzy) underneath many advantages that it has, like [5]:

Fuzzy controllers can cover a far wider variety of operating conditions and might operate with unique varieties of noise and disturbance, which is why they are extra strong than PI controllers. Developing a fuzzy controller is less highly priced than growing a controller based on a model or other controller. Fuzzy controllers are customizable because it is less complicated to recognize and trade their policies. That no longer handiest use the approach of the human operator, but are also expressed in natural linguistic terms. It is smooth to learn how fuzzy controllers paintings and the way to create them and observe them to a concrete software.

The work presented in this paper is used in exploitation of the fuzzy logic theory while an optimized fuzzy logic controller is designed so one can adjust the stator active and reactive powers float of a DFIG connected to an effective grid [6].

\section{MODELING OF THE WIND TURBINE}

Windmills produce electrical power the use of wind strength to run an electric generator. An air motion passes over the propellers, generating lift and exerting a rotational force. The rotating blades rotate a sluggish shaft of the nacelle, which enters a gearbox. The multiplier increases the rate of rotation and transmits it to the generator, which makes use of magnetic fields to transform the rotational electricity into electrical energy [7]. Precept of power transformation of a wind turbine, as proven in Figure 1.

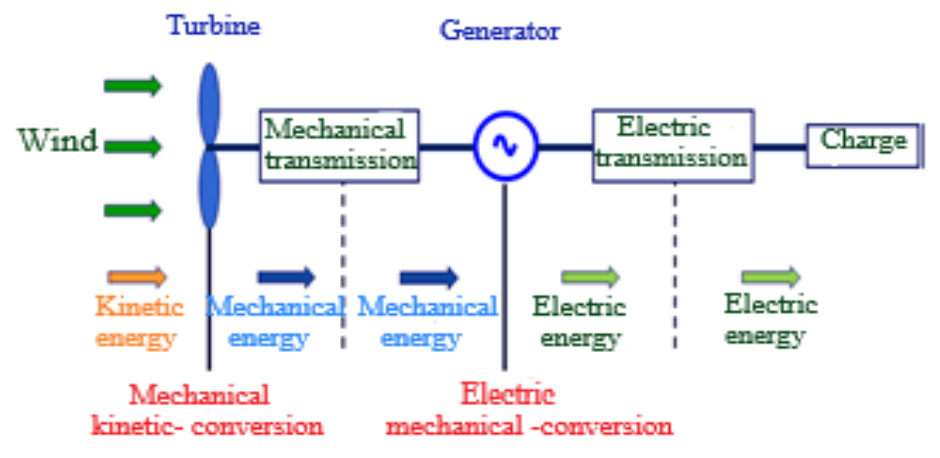

Figure 1. Principle of the energy transformation of a wind turbine.

We can determine the power available (theoretical power), due to the wind through applying the theory of the momentum and the theorem of Bernoulli:

$$
\mathcal{P}_{\text {disp }}=1 / 2 \cdot \rho \cdot \mathcal{S} \cdot v^{3}
$$

$\boldsymbol{S}$ : surface swept by the blades $\left[\mathrm{m}^{2}\right]$;

$\rho:$ density of the air $\rho=1.225 \mathrm{~kg} / \mathrm{m}^{3}$;

$v$ : pace of the wind $[\mathrm{m} / \mathrm{s}]$;

the mechanical electricity of the wind turbine is then:

Int J Pow Elec \& Dri Syst Vol. 11, No. 1, Mar 2020 : 263 - 274 


$$
\mathcal{P}_{\text {tur }}=C_{p}(\lambda, \beta) \cdot \frac{\rho \cdot \mathcal{S} \cdot v^{3}}{2}
$$

the maximum quantity of kinetic energy is defined by the limit of Betz:

$$
\mathcal{P}_{\text {tur }}=\mathcal{P}_{\text {max }}=\frac{16}{27} . \mathcal{P}_{\text {disp }}=0.59 . \mathcal{P}_{\text {disp }}
$$

the power coefficient is defined by:

$$
C_{p}=\frac{\mathcal{P}_{\text {tur }}}{\mathcal{P}_{\text {disp }}}
$$

The evolution of the $C p$ depends at the perspective of orientation of the blades $\beta$ and specific speed $\lambda$ :

$$
\lambda=\frac{\Omega_{t} \cdot R}{v}
$$

$\lambda$ : expresses the connection between velocity at the stop of the blades and the speed of the wind;

$\Omega_{t}$ : Number of revolutions before the multiplier;

$\mathrm{R}$ : ray of the blades of the aero generator;

$C p(\lambda, \beta)$ is called the coefficient reactivity power.

$$
C_{p}^{\max }(\lambda, \beta)=\frac{16}{27} \approx 0.593
$$

We can expressed the power coefficient $C p$ by $[8,9]$ :

$$
\begin{aligned}
& C_{1} \times\left(C_{2} \times \frac{1}{\lambda_{i}}-C_{3} \times \beta-C_{4}\right) \times \exp \left(-C_{5} \times \frac{1}{\lambda_{i}}\right)+C_{6} \times \lambda \\
& \frac{1}{\lambda_{i}}=\frac{1}{\lambda+0.08 \beta}-\frac{0.035}{\beta^{3}+1}
\end{aligned}
$$

The strength coefficient and therefore the torque decrease by way of greater than $\lambda$ by way of growing the pitch attitude [10].

Where:

$$
C_{\text {aer }}: \frac{\mathcal{P}_{\text {disp }}}{\Omega_{t}}=\frac{1}{2} \rho \cdot \mathcal{S} \cdot C_{p}(\lambda, \beta) v^{3} \frac{1}{\Omega_{t}}
$$

$C_{a e r}:$ Couples on the slow axis (side harnesses);

The role of the multiplier is to transmit the speed of the blades to the generator Figure 2.

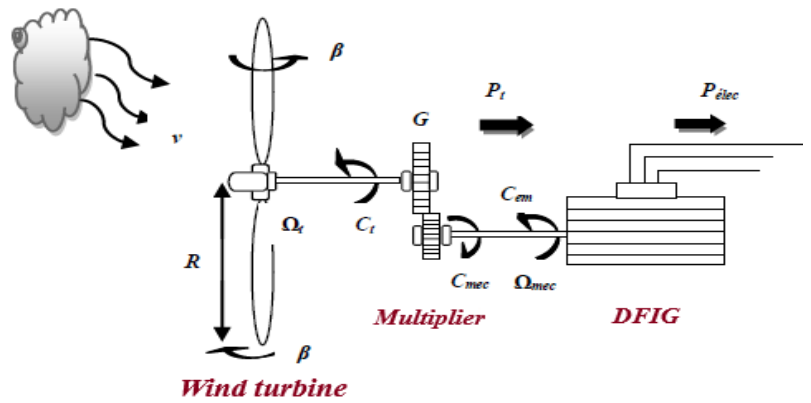

Figure 2. Structure of the wind system.

therefore, we can model the multiplier by the following equations:

$$
\mathrm{C}_{\mathrm{r}}=\frac{\mathrm{C}_{\mathrm{aer}}}{\mathrm{G}}
$$




$$
\Omega_{\text {turbine }}=\frac{\Omega_{\text {mer }}}{G}
$$

with: G: The report/ratio of the speed-increasing gear.

$$
\mathrm{J}=\frac{J_{\text {turbine }}}{G^{2}}+J_{r}
$$

to determine the evolution of the mechanical pace with part of the full torque $\left(C_{m e c}\right)$ implemented to the rotor, we use the essential equation of the dynamics:

$$
\mathrm{J} \times \frac{d \Omega_{m e c}}{d t}=C_{m e c}
$$

the coefficient of the multiplier links the mechanical velocity to the wide variety of revolutions of the turbine and connects the torque on the slow axis to the torque on the quick axis.

In which: $\mathrm{J}$ is the whole inertia, which seems on the rotor of the generator. This torque takes under consideration, the electromagnetic couple (Cem) produced through the generator, the couple of viscous frictions (Cvis) and couples it (Cr).

$$
C_{m e c}=C_{r}-C_{e m}-C_{v i s}
$$

The coefficient of viscous frictions $\mathrm{F}$ model the resistive torque due to frictions as:

$$
C_{v i s}=f \times \Omega_{m e c}
$$

One can model the tree like following:

$$
\frac{C_{a e r}}{G}-C_{e m}=\left(\frac{J_{T}}{G^{2}}+J_{g}\right) \frac{d \Omega_{g}}{d t}+\left(\frac{f_{T}}{G^{2}}+f_{g}\right) \Omega_{g}
$$

$C_{a e r}$ and $C_{e m}$ : The wind couple and the electromagnetic couple.

$J_{g}$ and $J_{\text {turbine }}$ : The inertia of the generator and that of the turbine.

$f_{T}$ and $f_{g}$ : The coefficient of viscous frictions of the turbine and that of the generator.

$\Omega_{g}$ : Number of revolutions of the generator (fast axis).

We put:

$$
\begin{aligned}
& \frac{J_{T}}{G^{2}}+J_{g}=J \\
& \frac{f_{T}}{G^{2}}+f_{g}=f
\end{aligned}
$$

From where, the mechanical equation becomes:

$$
\frac{C_{a e r}}{G}-C_{G}=J \frac{D \Omega_{g}}{d t}+f \Omega_{g}
$$

\section{TURBINE SIMULATION RESULTS}

Figure 3 shows the profile of the wind that will be applied for the wind turbine its low value is around $(8 \mathrm{~m} / \mathrm{s})$. The simulation results shows the influence of the variation of the mechanical velocity as a characteristic of the wind pace on the electrical strength produced in Figure 4.

Through the evolution of the power coefficient Figures 5, we are able to note that this one is approximately its theoretical maximum value. This coefficient is obtained for a fixed angle $\beta(\beta=20)$ that gives us an optimal $\lambda$. It is noted that it reaches a maximum value of 0.5 . This simulation effects show the reliability of the manipulation without servo controlling of the wind pace.

Int J Pow Elec \& Dri Syst Vol. 11, No. 1, Mar 2020 : $263-274$ 


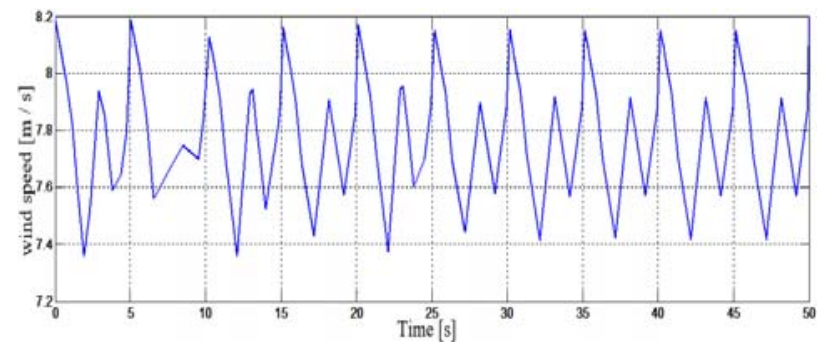

Figure 3. Wind profile implemented to the turbine.
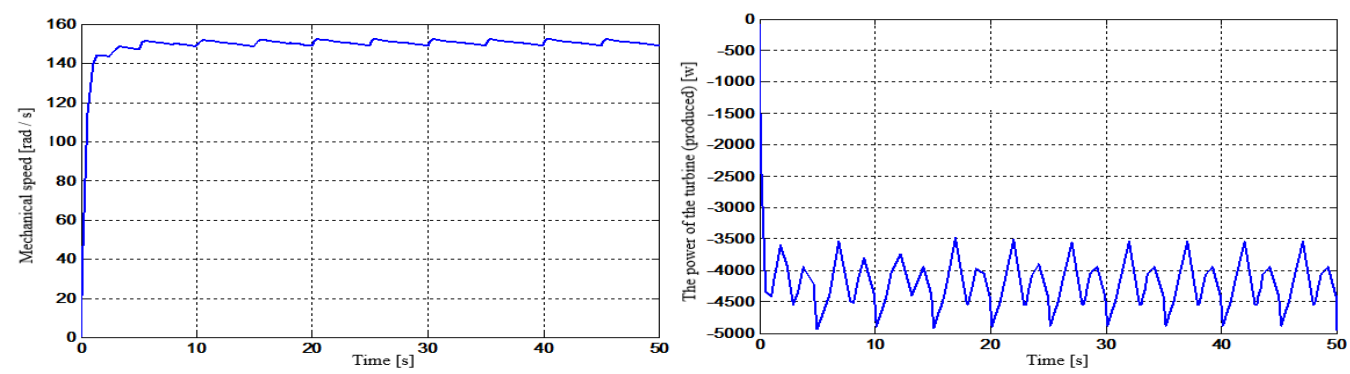

Figure 4. The mechanical speed and the power produced.
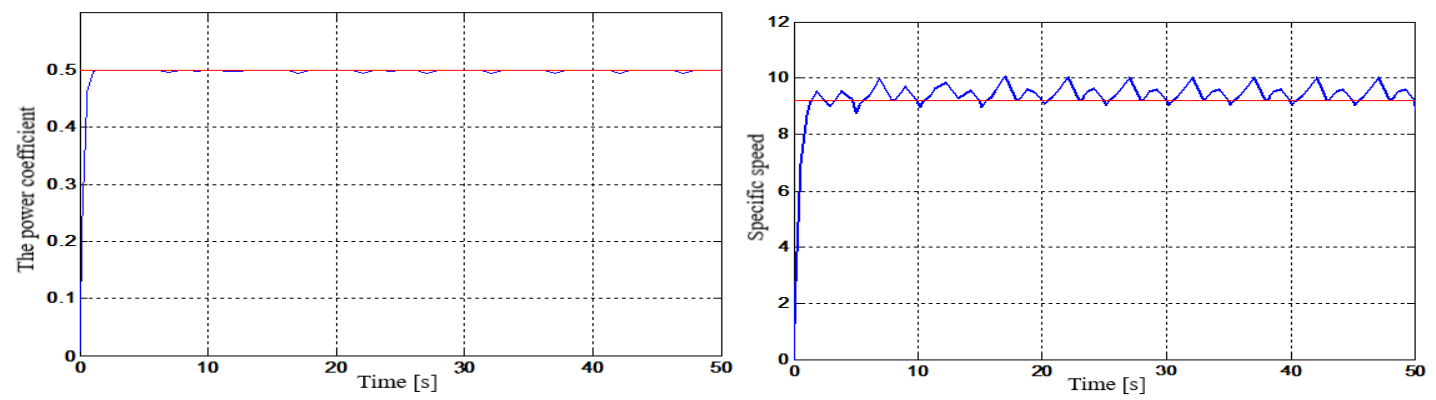

Figure 5. The power coefficient and the specific speed.

\section{MODELING OF THE DFIG}

It is essential to apply a particular and simple model for a higher illustration of the behavior of a dual-feed induction generator. The two-section models $(\mathrm{d}, \mathrm{q})$ given by way of the park transformation are used [11].

\subsection{Model of DFIG in the referential $(d, q)$}

The DFIG is used as the generator selected for the wind system in addition, the DFIG controlled by inverters through its rotor operates over a number $\pm 30 \%$ variation across the synchronous pace. This desire permits the converters dimensioned to transit $30 \%$ of nominal energy. Consequently, it is going to be financial [12]. The model of the DFIG is expressed in the (dq) reference frame via the following equations [13-15].

We have: $\quad \theta_{s}=\theta_{r}+\theta \Rightarrow=\theta=\theta_{s}-\theta_{r}$

So: $\begin{aligned} \quad & \frac{d \theta}{d t}=\frac{d \theta_{s}}{d t}-\frac{d \theta_{r}}{d t} \\ & \Rightarrow \omega=\omega_{\mathrm{s}}-\omega_{\mathrm{r}}\end{aligned}$ 


\subsection{Electric equations}

$$
\left\{\begin{array}{c}
V_{s d}=R_{s} I_{s d}+\frac{d \varphi_{s d}}{d t}-\omega_{s} \varphi_{s q} \\
V_{s q}=R_{s} I_{s q}+\frac{d \varphi_{s q}}{d t}+\omega_{s} \varphi_{s d} \\
V_{r d}=R_{r} I_{r d}+\frac{d \varphi_{r d}}{d t}-\left(\omega_{s}-\omega\right) \varphi_{r q} \\
V_{r q}=R_{r} I_{r q}+\frac{d \varphi_{r q}}{d t}+\left(\omega_{s}-\omega\right) \varphi_{r d}
\end{array}\right.
$$

With respectively:

$V_{s d}, V_{s q}, V_{r d}$ and $V_{r q}$ are the direct and quadrature stator and rotor voltages of the two-phase system. $\omega_{r}$ and $\omega_{s}$ are the pulsations of the stator and rotor electrical magnitudes.

\subsection{Magnetic equations}

$$
\left\{\begin{array}{l}
\varphi_{s d}=L_{s} I_{s d}+M I_{r d} \\
\varphi_{s q}=L_{s} I_{s q}+M I_{r q} \\
\varphi_{r d}=L_{r} I_{r d}+M I_{s d} \\
\varphi_{s d}=L_{r} I_{r q}+M I_{s q}
\end{array}\right.
$$

With:

$\varphi_{s q}, \varphi_{s d}, \varphi_{r q}$ and $\varphi_{r d}:$ Are stator and rotor flow direct and in squaring of the diphasic system;

$L_{s}=l_{s}-M_{s}$ : The stator cyclic inductance;

$L_{r}=l_{r}-M:$ The rotor cyclic inductance;

$M=\frac{3}{2} M_{s r}$ : Cyclic mutual inductance between stator and rotor.

\subsection{Mechanical equation}

$$
C_{e m}=C_{r}+f \Omega+J \frac{d \Omega}{d t}
$$

With respectively:

$C_{e m}$ : The electromagnetic couple;

$C_{r}$ : The resistive torque;

$f$ : The coefficient of viscous friction of the DFIG;

$j:$ The inertia of the revolving parts;

$\Omega$ : Number of revolutions of the axis of the DFIG.

The expression of the electromagnetic couple is given through:

$$
\left\{\begin{array}{c}
C_{e m}=-p\left(I_{s q} \varphi_{s d}-I_{s d} \varphi_{s q}\right) \\
C_{e m}=-p \frac{M}{L_{r}}\left(I_{s q} \varphi_{r d}-I_{s d} \varphi_{r q}\right) \\
C_{e m}=p \frac{M}{L_{s}}\left(I_{r q} \varphi_{s d}-I_{r d} \varphi_{s q}\right)
\end{array}\right.
$$

\subsection{Active and reactive powers}

$$
\begin{gathered}
\left\{\begin{array}{l}
P_{s}=-V_{s d} I_{s d}-V_{s q} I_{s q} \\
Q_{s}=-V_{s q} I_{s d}+V_{s d} I_{s q}
\end{array}\right. \\
\left\{\begin{array}{l}
P_{r}=V_{r q} I_{r q}+V_{r d} I_{r d} \\
Q_{r}=V_{r q} I_{r d}-V_{r d} I_{r q}
\end{array}\right.
\end{gathered}
$$

\section{VECTOR CONTROL OF THE ACTIVE AND REACTIVE POWERS OF THE DFIG} currents via:

The arrangement of the (20) and (21) offers the expression of the rotor voltages in line with the rotor 


$$
\left\{\begin{array}{l}
V_{r d}=R_{r} I_{r d}+\left(L_{r}-\frac{M^{2}}{L_{s}}\right) \frac{d I_{r d}}{d t}-g \omega_{s}\left(L_{r} \frac{M^{2}}{L_{s}}\right) I_{r q} \\
V_{r q}=R_{r} I_{r q}+\left(L_{r}-\frac{M^{2}}{L_{s}}\right) \frac{d I_{r q}}{d t}-g \omega_{s}\left(L_{r} \frac{M^{2}}{L_{s}}\right) I_{r d}+g \frac{M V_{s}}{L_{s}}
\end{array}\right.
$$

we can present the equation of torque is as follows:

$$
C_{e m}=p \frac{M}{L_{s}}\left(I_{r q} \varphi_{s d}-I_{r d} \varphi_{s q}\right)
$$

we can described the furnished active and reactive energy as follows:

$$
\left\{\begin{array}{l}
P_{s}=V_{s d} I_{s d}+V_{s q} I_{s q} \\
Q_{s}=V_{s q} I_{s d}-V_{s d} I_{s q}
\end{array}\right.
$$

adopting the belief of a negligible stator resistance Rs and the stator flux is constant and orientated along the axis, we deduce:

$$
\begin{aligned}
& \varphi_{s d}=\varphi_{s} \text { And } \quad \varphi_{s q}=0 \\
& \left\{\begin{array}{l}
V_{s d}=\frac{d \varphi_{s}}{d t}=0 \\
V_{s q}=V_{s} \omega_{s} \varphi_{s}
\end{array}\right.
\end{aligned}
$$

the stator active and reactive energy may be expressed as follows:

$$
\begin{aligned}
& P_{s}=-V_{s} \frac{M}{L_{s}} I_{r q} \\
& Q_{s}=\frac{V_{s}{ }^{2}}{L_{s} \omega_{s}}-V_{s} \frac{M}{L_{s}} I_{r d}
\end{aligned}
$$

The closing equations display that the active and reactive powers can be controlled via rotor currents. Thus, the rotor voltages inside the $\mathrm{d}-\mathrm{q}$ axis may be written as follows:

$$
\begin{aligned}
V_{r d}=\left(\frac{R_{r} L_{s}+\sigma L_{s} L_{s} S}{M V_{s}}\right)\left(Q_{s}-\frac{V_{s}^{2}}{\omega_{s} L_{s}}\right)-\omega_{r} L_{r} \sigma I_{r q} \\
V_{r q}=\left(\frac{R_{r} L_{s}+\sigma L_{s} L_{r} S}{M V_{s}}\right) P_{s}+\omega_{r} L_{r} \sigma I_{r d}+\omega_{r} \frac{M V_{s}}{\omega_{s} L_{s}}
\end{aligned}
$$

$\boldsymbol{\sigma}:$ the leakage coefficient, it is given by:

$\boldsymbol{\sigma}=1-\frac{M^{2}}{L_{s} L_{r}}$

\subsection{PI control of the DFIG}

We will establish a manage loop on every power with an impartial regulator (PI) even as compensating for the disturbance terms due to the fact currents and voltages are linked by way of a switch function of first order. Because the slip cost is low.

The proportional Integral controller (PI) is still the maximum generally used for controlling the DFIG [16], as well as in lots of business manage structures. It is simple and quick to put into effect even as providing ideal performance [17]. Regulators every axis position is to get rid of the gap among the active and reactive strength references and the measured active and reactive strength. The synthesis of PI controllers is offered in [18].

\subsection{Direct control of active and reactive powers}

This approach uses two PI controllers to control the system; we can configure a manipulate loop of every energy (Ps and Qs) with an independent controller at the same time as compensating for the perturbation phrases. Because of the low slip price, we neglect the terms coupling among the two manipulate axes. We acquire a vector control with an unmarried controller in line with axis, shown in Figure 6, [19, 20$].$ 


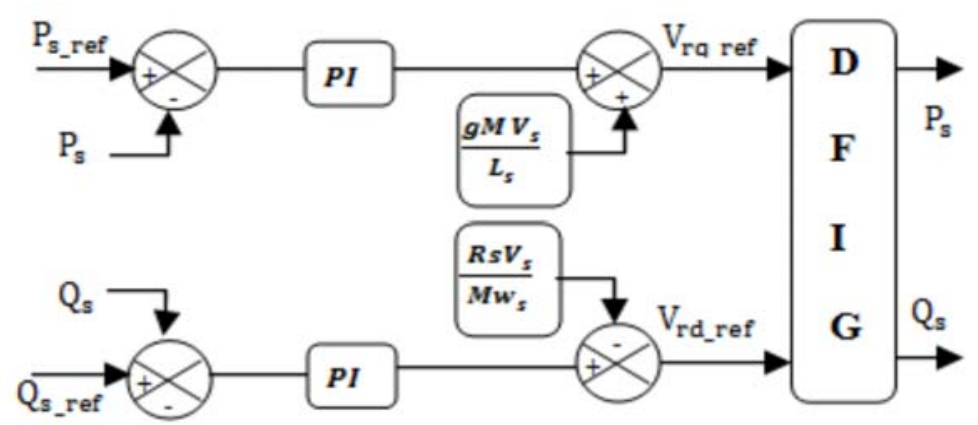

Figure 6. Block diagram of the direct control

\subsection{Indirect control of active and reactive power}

5.3.1. Indirect control loops without the power

It is necessary that the rotor currents irq and ird, respectively the pix of the active and reactive powers of the stator, Ps and Qs, maintain their contemporary references, [19].

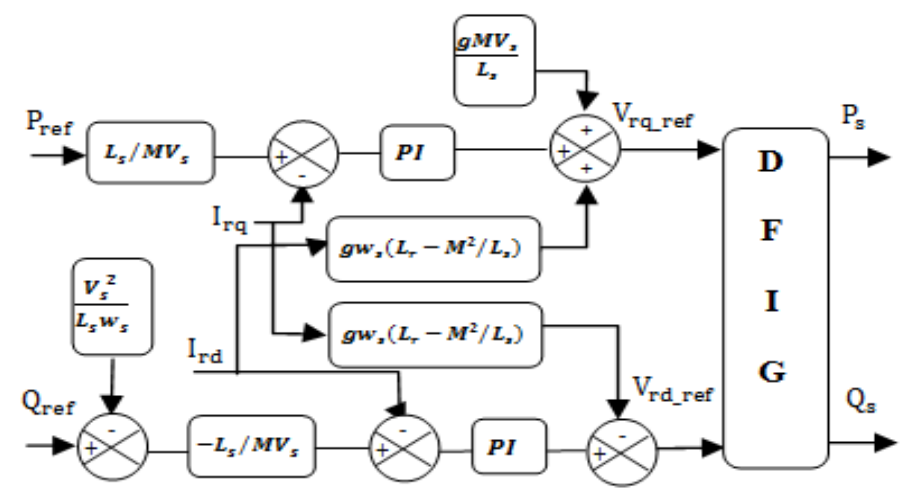

Figure 7. Representation of a block diagram of indirect control in open loop

\subsubsection{Indirect control loops with the powers}

We are able to comprise an extra manipulate loop to the powers in order to dispose of the static error whilst maintaining the dynamics of the machine, to enhance the preceding control Figure 8 [20].

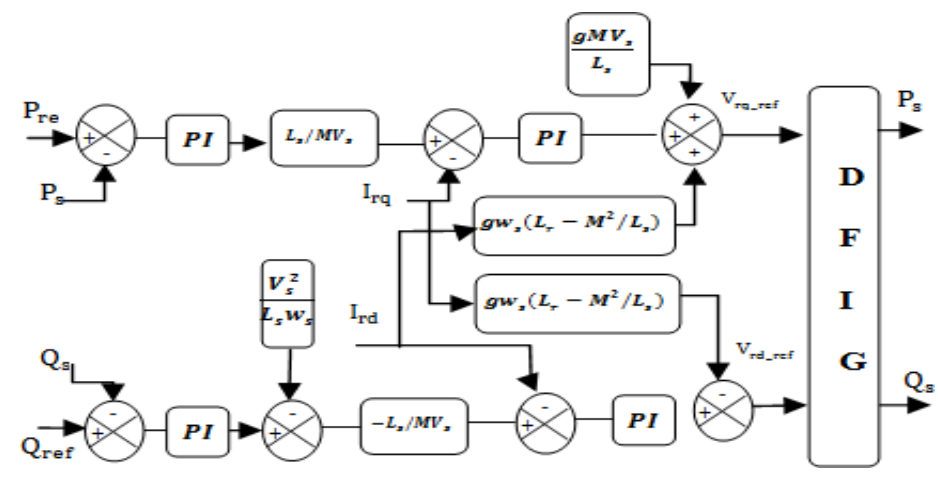

Figure 8. Representation of a block diagram of indirect control in closed loop 


\subsection{Simulation results}

The distinct curves received with the aid of controlling the active and reactive power generated in the stator of the DFIG are supplied in Figure 9 and 10. We are able to see the good response of the energy manipulate of the DFIG.

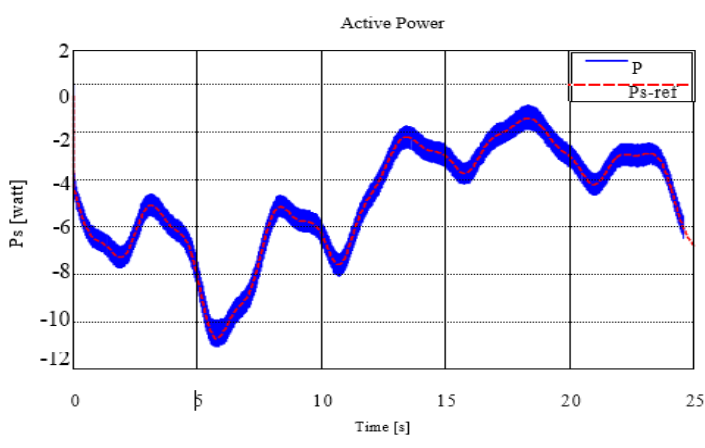

Figure 9. Active power Ps [Watt]

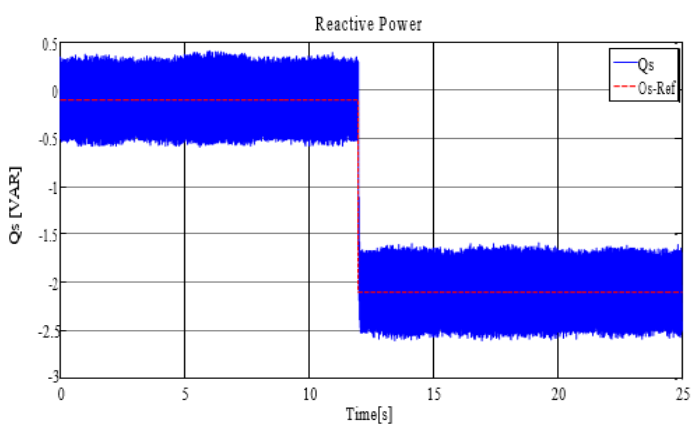

Figure 10. Reactive power Qs [VAR]

\section{FUZZY CONTROL OF THE DFIG}

Fuzzy logic succeeds in supplying exceptional performance without resorting to the mathematical model of the system, truly with the aid of incorporating the information of the professionals. Therefore, fuzzy manage procedures to a positive volume the ability of human reasoning [21].

As proven in Figure 11, the fuzzy manipulate is based at the Mamdani model. This mechanism is subdivided into several levels:

a. Initialization is the definition of linguistic variables and phrases; build the membership features and the rule base.

b. Fuzzification is the conversion of unique input facts into fuzzy values membership functions.

c. The inference is evaluation of policies of the rule of thumb base and combine the consequences of each rule.

d. Defuzzification is convert the output information to non-fuzzy values.

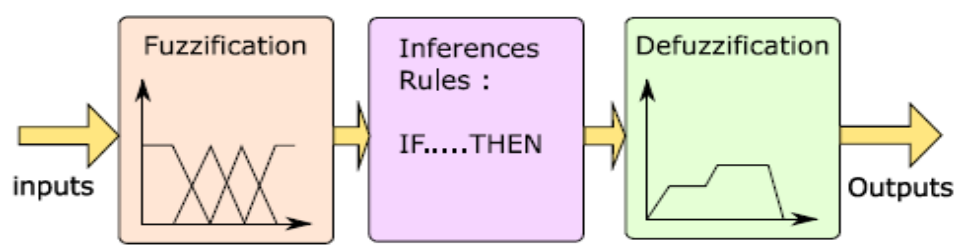

Figure 11. Block diagram of fuzzy control

A block diagram wherein fuzzy controllers are included into the DFIG vector manage block is shown in figure 12. Each fuzzy controller gives unbiased control of the active and reactive powers. Figure 13 illustrates the layout of the fuzzy controller. The profits $G_{e} G_{\Delta e}$ and $G_{\Delta u}$ are scale factors (normalization). To attain appropriate control we vary these elements. Indeed, they will determine the performance of the control.

Usually, we pick a few parameters which includes linguistic variables, membership functions, and inference technique and defuzzification strategy that allows you to layout a fuzzy controller for the manipulation of electrical drives [22]. We take as inputs the error and its spinoff, at the same time as the output is the command itself. The triangular and trapezoidal membership features are used in a normalized speech universe inside the interval $[-1 ; 1]$ for every variable, as proven in Figures 14 and 15, respectively for inputs (mistakes, errors variant) and output (input procedure). 


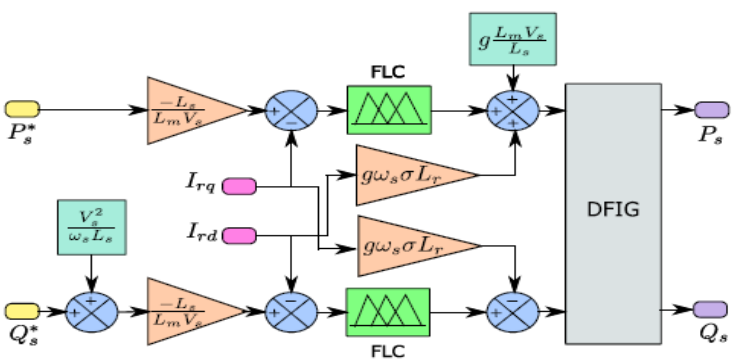

Figure 12. Fuzzy control of DFIG.

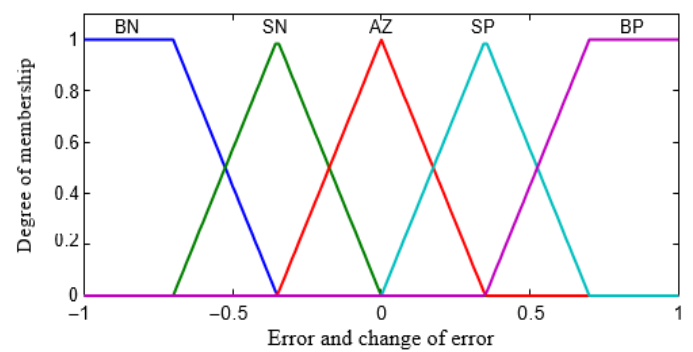

Figure 14. Membership functions of error and change of error

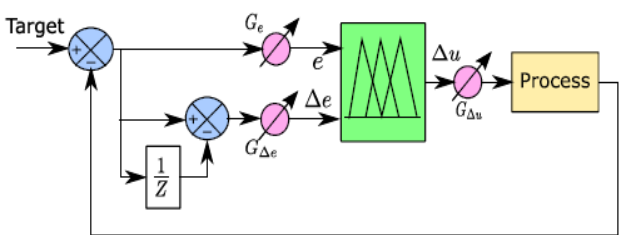

Figure 13. Design of a fuzzy controller.

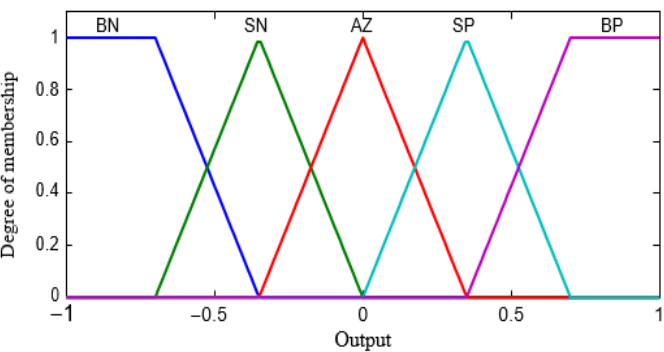

Figure 15. Membership functions of output

The subsets fuzzy membership was noted as follows:

BN: Big-Negative;

SN: Small-Negative;

AZ: About-Zero;

SP: Small-Positive;

BP: Big- Positive.

The fuzzy regulations, for figuring out output variable of the controller as a characteristic of enter variables are grouped within Table 1.

Table 1. Inference matrix

\begin{tabular}{|c|c|c|c|c|c|c|}
\hline \multirow{2}{*}{\multicolumn{2}{|c|}{$\Delta \mathrm{u}$}} & \multicolumn{5}{|c|}{$\mathrm{e}$} \\
\hline & & $\mathrm{BN}$ & $\mathrm{SN}$ & $\mathrm{AZ}$ & SP & BP \\
\hline \multirow{5}{*}{$\Delta \mathrm{e}$} & $\mathrm{BN}$ & $\mathrm{BN}$ & $\mathrm{BN}$ & SN & SN & $\mathrm{AZ}$ \\
\hline & $\mathrm{SN}$ & $\mathrm{BN}$ & $\mathrm{SN}$ & SN & $\mathrm{AZ}$ & $\mathrm{SP}$ \\
\hline & $\mathrm{AZ}$ & $\mathrm{BN}$ & $\mathrm{SN}$ & $\mathrm{AZ}$ & SP & BP \\
\hline & $\mathrm{SP}$ & $\mathrm{BN}$ & $\mathrm{AZ}$ & SP & SP & BP \\
\hline & $\mathrm{BP}$ & $\mathrm{AZ}$ & $\mathrm{SP}$ & SP & BP & BP \\
\hline
\end{tabular}

\section{SIMULATION RESULTS} controller

Figures 16, 17, 18 show that the performance of fuzzy logic is quite good in comparison with PI 


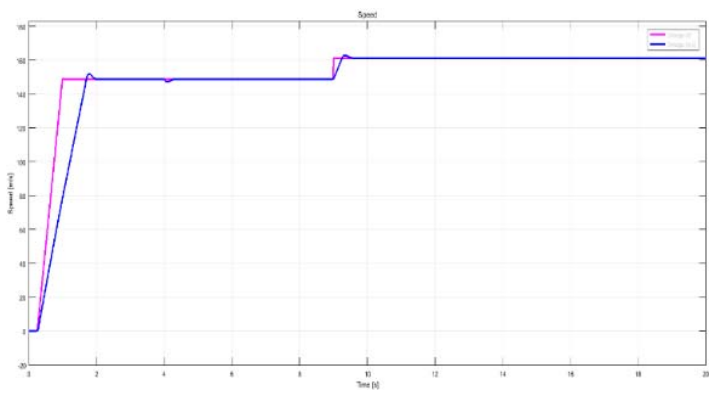

Figure 16. Speed of the device.
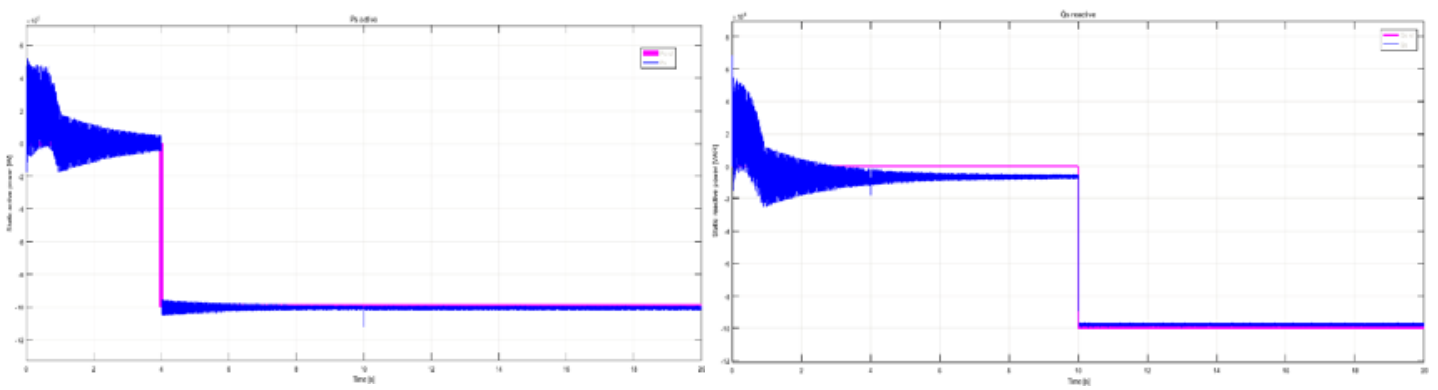

Figure 17. Active and reactive power stator.
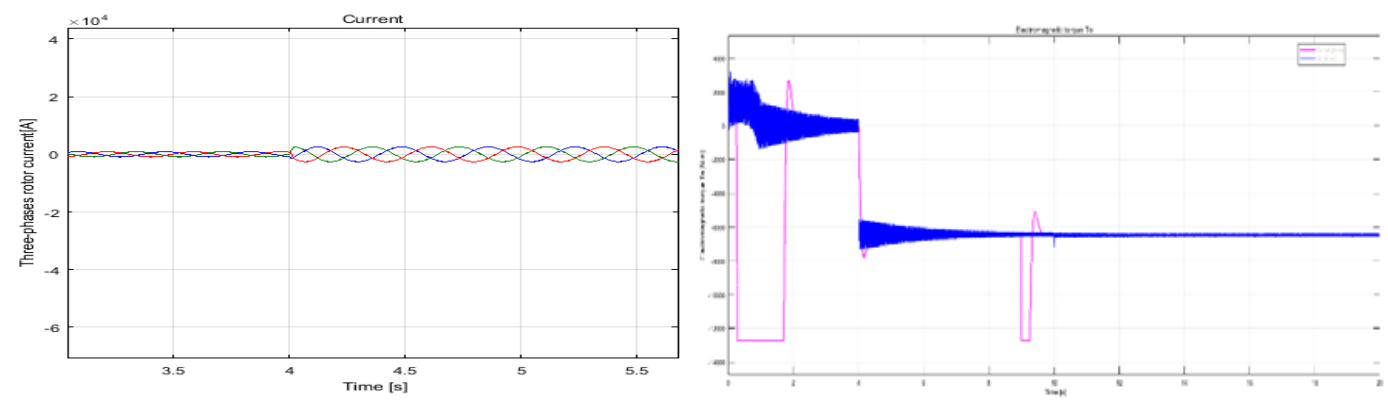

Figure 18. Three-phase rotor currents and electromagnetic torque.

\section{CONCLUSION}

This article presents the control with fuzzy logic of the active and reactive powers of a DFIG dedicated to a wind device. First, the thought of a version of the turbine and the generator. Then, presentation of a manage strategy based on fuzzy control and PI controllers permitting independent manipulate of the power. By comparing the performance of the PI and fuzzy controllers, it is far clear, that the fuzzy manipulate is strong against the parametric variations of the machine and gives a fast convergence, unaffected by using the noise and the spurious indicators calculator. In addition, the fuzzy control of the DFIG has exquisite overall performance and improves the energy high quality and stability of the wind turbine compared to the PI controller.

\section{REFERENCES}

[1] Ki Kim, S., E. Sang Kim, J. Young Yoon and H. Yong Kim, "PSCAD/EMTDC based dynamic modelling and analysis of a variable speed wind turbine," IEEE Power Engineering Society General Meeting, pp: 1735-1741. 2004.

[2] Bekakra Y, Attous D B, "Sliding mode controls of active and reactive power of a DFIG with MPPT for variable speed wind energy conversion," Australian Journal of Basic and Applied Sciences, Vol. 5, No. 12, pp. 2274-2286, 2011. 
[3] Cheikh R, Drid S, Menacer A., "The doubly fed induction generator powers flow control in variable speed," in Proceedings of 6th International Conference on Electrical Engineering, 2010.

[4] Ourici A., "Power control in a doubly fed induction machine," World Academy of Science. Engineering and Technology, Vol. 77, No. 53, pp. 51-54, 2011.

[5] Reznik L., "Fuzzy Controllers," Elsevier: Newnes, 1997 -Through Voltage Dips. Power Electronics and Applications, EPE’09, pp. 1-10, 2009.

[6] Chung G B, Choi J., "Application of fuzzy PI control algorithm as stator power controller of a double-fed induction machine in wind power generation," Journal of Power Electronics, Vol. 9, No. 1, pp. 109-116, 2009.

[7] N. Zerzouri, H. Labar, "Active and Reactive Power Control of a Doubly Fed Induction," International Journal of Power Electronics and Drive System (IJPEDS), Vol. 5, No. 2, pp. 244-251, 2014.

[8] Robert Gasch, Jochen Twele, "Wind Power Plants: Fundamentals, Design, Construction and Operation," Springer, 2012.

[9] LP Colas, F Francois, B Yong Dong Li, "A Modified Vector Control Strategy for DFIG Based Wind Turbines to Ride-Through Voltage Dips," Power Electronics and Applications, EPE’09, pp. 1-10, 2009.

[10] G. Venu Madhav, Y. P. Obulesu, "A Fuzzy Logic Control Strategy for Doubly Fed Induction Generator for Improved Performance under Faulty Operating Conditions," International Journal of Power Electronics and Drive System (IJPEDS), vol. 4, no. 4, pp. 419 -429, 2014.

[11] M. Lamnadi, M. Trihi, B. Bossoufi and A. Boulezhar, "Modelling and Control of a Doubly-Fed Induction Generator for Wind Turbine-Generator Systems," International Journal of Power Electronics and Drive System (IJPEDS), vol. 7, No. 3, pp. 982-995, 2016.

[12] F. Poitiers, B. Toufik, and A. Machmoum, "Advanced control of a doubly-fed induction generator for wind energy conversion," Electric Power Systems Research, No. 79, pp. 1085-1096, 2009.

[13] H. Bekka, S. Taraft, D. Rekioua, and S. Bacha, "Power control of a wind generator connected to the grid in front of strong winds," Journal of Electrical Systems, Vol. 3, No. 9, pp. 267-278, 2013.

[14] D. Rekioua, "Wind power electric systems: Modeling, simulation and control, green energy and technology," Springer, 2014.

[15] A. Boyette, P. Poure, S. Saadate, "Direct and indirect control of a doubly fed induction generator wind turbine including a storage unit," in 32th edition of Industrial Electronics Conference IECON'2006, IEEE, pp. 2517-2522, 2006.

[16] M. Lopez, "Contribution à l'optimisation d'un système de conversion éolien pour une unité de production isolée," Ph.D. dissertation, Sciences et Technologies de l'Information des Télécommunications et des Systèmes Université Paris Sud 11, 2008.

[17] G. A. Smith and K. A. Nigim, "Wind-energy recovery by a st atic scherbius induction generator," in Proc. IEE, pp. 317-324, 1981.

[18] N. Cherfia, D. Kerdoun, and A. Boumassata, "Correction of the mechanical speed for the dfig wind turbine," International Journal of Research in Engineering and Technology, Vol. 2, pp. 29-38, 2014.

[19] Forchetti D, Garcia G, Valla MI, "Vector control strategy for a doubly fed standalone induction generator," in IEEE 28th annual conference of the industrial electronics society, 2002.

[20] A. Petersson, "Analysis, modeling and control of doublyfed induction generators for wind turbines," Ph.D. Thesis, Chalmers University of Technology, Goteborg, Sweden, 2005.

[21] H. K. Davijani, A. Sheikholeslami, H. Livani, and M. K. Davijani, "Fuzzy logic control of doubly fed induction generator wind turbine," World Applied Sciences Journal, Vol. 6, No. 4, pp. 499-508, 2009.

[22] M. Godoy, B. Simges, K. Bose, R. J. Spiegel, "Fuzzy logic based intelligent control of a variable speed cage machine wind generating system," in PESC, 1995.

Int J Pow Elec \& Dri Syst Vol. 11, No. 1, Mar 2020 : $263-274$ 